\title{
Modification of a cement binder in structural concrete for mine and underground construction
}

\author{
Andrey Uglyanitsa $^{1^{*}}$, and Vladimir Duvarov ${ }^{1}$ \\ ${ }^{1}$ T.F. Gorbachev Kuzbass State Technical University, Str. Vesennyaya 28, Kemerovo, Russian Feder- \\ ation, 650000
}

\begin{abstract}
The issues of the modification of a binder in structural cement concrete for mine and underground construction with wastes of chemical enterprises are considered in the article. Hundreds of tons of waste are generated annually at chemical enterprises of the Russian Federation, polluting the environment and requiring their disposal. The performed studies deal with the improvement of physical and mechanical properties of a cement binder with a dispersed manganese sludge modifier, which is a waste product of ammonia or methanol production, for its use in mine and underground construction. As a result of the studies performed, it was found that the addition of dispersed sludge with manganese oxide in an amount of $4 \%$ of the cement mass to a cement binder leads to the activation of the cement hydration process, while the rate of development of the plastic strength of the cement stone structure increases, the period of its structure formation reduces and the compressive cement stone strength increases by $17-18 \%$, which makes it possible to reduce the cement content in structural concrete by $8.8-10.0 \%$ while maintaining its strength, reducing the cost of mine and underground structures and, as a result, reducing the cost of mining.
\end{abstract}

\section{Introduction}

The volume of coal production increases annually in the Kemerovo region - Kuzbass; for example, the volume of coal production increased by $20 \%$ over the past 5 years [1-2]. Increasing and maintaining such a volume of coal production requires the construction of a large number of various mine and underground structures. A large number of various building materials are used in mine and underground construction, cement concrete being one of the main ones [3-4]. Currently, the linings of almost all permanent structures in mine and underground construction are made of monolithic or prefabricated cement concrete or reinforced concrete, which causes large volumes of its consumption

\footnotetext{
*Corresponding author: uav@,kuzstu.ru
} 
The cost of cement concrete used determines the cost of mine and underground structures, and, accordingly, the cost of mining, which is very important when the market value of coal and ore decreases [5-6].

Due to the large volumes of coal production in the Kemerovo region - Kuzbass, the governor presented a new environmental standard - "Clean coal - Green Kuzbass", the implementation of which requires to minimize the environmental damage in the coal mining region [7-8]. To solve this problem, it is possible to reuse waste from various industries as raw materials for the production of various building materials, which allows simultaneously solving two problems: waste disposal and reducing the extraction of raw materials for the production of new building materials [9-11]

Portland cement is used as a binder for mixing cement concrete in mine and underground construction. To improve physical and mechanical properties of a cement binder, the following modifiers are often added to cement: surfactants, electrolytes, polymer additives and others; but these modifiers have a rather high cost, require additional resources for their production and pollute the environment with waste from their production. Many scientists have been involved in improving properties of cement and the cement matrix of concrete with the help of fine mineral admixtures [12-15].

Every year, chemical enterprises of the Russian Federation generate hundreds of tons of anthropogenic waste in the form of dispersed sludge from spent catalysts, which requires its recycling. So, for example, up to 25 tons of manganese sludge is generated annually during ammonia and methanol production at JSC "Azot" in Kemerovo.

The use of various industrial waste products for the production of cement mortars and concretes and has been studied for a number of years in KuzSTU [16-18]. It was found that the addition of dispersed sludge containing transition metal oxides to a cement binder can increase the cement stone strength and improve its other physical and mechanical properties. The results of these studies made it possible to formulate a working hypothesis that the addition of dispersed sludge with manganese oxide into a cement binder will intensify the processes of cement hardening and strength development, improve the strength and other physical and mechanical properties of the cement stone. In order to test this hypothesis, laboratory studies were carried out to reveal the rules for regulating the processes of hydration, structure formation and hardening of a cement binder modified with dispersed sludge with manganese oxide.

\section{Research methods}

Topkinsky Portland cement CEM I $42.5 \mathrm{~N}$ based on clinker with a C3S content of $67.35 \%$, C2S - $10.67 \%$, C3A - 5.7\%, C4AF - 13.13\% was used for mixing the cement paste. Quartz sand was used as a fine aggregate for the cement-sand mortar according to GOST 87362014. Sand fineness modulus was $F m=1.83$, total residue on a sieve No. $063-11.3 \%$, content of particles less than $0.16 \mathrm{~mm}-1.4 \%$. Manganese sludge from JSC "Azot", Kemerovo was used as an admixture. Before use, sludge was dried to a minimum residual moisture at a temperature of 105 degrees and ground in a ball mill until the residue on a sieve No. 008 of no more than $15 \%$. The resulting manganese sludge admixture was a fine powder with a specific surface of $350 \mathrm{~m}^{2} / \mathrm{kg}$, a true density of $4800 \mathrm{~kg} / \mathrm{m}^{3}$ and a bulk density of 2920 $\mathrm{kg} / \mathrm{m}^{3}$, containing in its composition: iron (II) oxide $17.0-18.0 \%$, manganese oxide 74.0 $75.0 \%$, sodium oxide $8.0-9.0 \%$ and insoluble residue.

To determine the effect of the manganese sludge admixture on the compressive strength of the cement stone, samples were made in the form of cubes with dimensions of $2 \times 2 \times 2$ $\mathrm{cm}$. All samples were hardened under normal conditions. The sludge admixture was added in an amount of $0-12 \%$ of the cement mass in $1 \%$ increments in accordance with GOST 30744-2001. The minimum number of identical samples of the cement stone was taken 
equal to 10 , and the minimum number of identical samples in each series of experiments during testing was taken equal to 12 . The ultimate strength was determined using a PSU-10 press as the arithmetic mean of test results.

The class of Portland cement without admixtures and with sludge admixtures was determined by the ultimate compressive strength according to GOST 30744-2001 on test beams with dimensions of $4 \times 4 \times 16 \mathrm{~cm}$, made in three-cavity metal molds from the cementsand mortar with 1:3 water-to-cement ratio by weight, determined according to GOST 30744-2001. Before testing, the samples were cured in accordance with the GOST requirement for 28 days. The sludge admixture was added in the amount of $0-12 \%$ of the cement mass in $1 \%$ increments. The minimum number of identical samples in each series of experiments during testing was taken equal to 12 in accordance with GOST 30744-2001. According to GOST, the compressive strength was first determined using a MII-100 device as the arithmetic mean of the results of tests of six beam samples, and then the strength class of Portland cement was determined using a MS-500 hydraulic press by testing twelve halves of the test beam samples obtained after the compressive strength tests of six samples.

To study the effect of the sludge admixture on kinetics of the cement paste structure formation, the plastic strength of the cement paste was determined without and with the sludge admixture in the amount at which the most durable cement stone was obtained in studies to determine its strength.

The plastic strength (ultimate shear stress) of the cement paste was determined with a lever-type conical plastometer of the Moscow State University design by immersing a meal cone with an angle of $30^{\circ}$ into the hardening cement paste as the arithmetic mean of the results of three tests.

The study of the period of structure formation of the hardening cement paste and the cement-sand mortar was carried out without and with the sludge admixture in the amount at which the most durable cement stone was obtained in studies to determine the compressive strength of the cement stone.

Kinetics of hardening processes at the stage of the formation of the coagulation structure of the cement paste and the cement-sand mortar was studied by the electron-acoustic method. The measurement of the velocities of propagation of longitudinal elastic waves in the cement paste and the cement-sand mortar was carried out using an ultrasonic device UK14-PM. The velocities of propagation of longitudinal elastic waves in the cement paste and the cement-sand mortar were determined on samples with dimensions of $0.04 \times 0.04 \times 0.16 \mathrm{~m}$ without and with the sludge admixture every 20 minutes for 14 hours according to the results of tests of six samples.

The end of the time of the structure formation of the hardened samples of the cement paste and the cement-sand mortar was recorded at the moment of a sharp increase in the velocity of propagation of elastic waves, which corresponded to a sharp upward bend in the curve of the ultrasound propagation velocity versus time. 14 hours after mixing the cement binder with water, changes in the velocity of propagation of longitudinal elastic waves in the structured cement paste and the cement-sand mortar due to the addition of manganese oxide sludge to the cement binder were recorded.

The study of heat release kinetics during the Portland cement hydration was carried out without and with the sludge admixture in the amount at which the most durable cement stone was obtained in studies to determine the compressive strength of the cement stone with the sludge admixture. Heat release kinetics was determined using BKS-2X diathermic calorimeter by changing the temperature of the cement paste with and without the sludge admixture at $\mathrm{W} / \mathrm{C}=0.5$. The temperature was measured for 3 days. 


\section{Results and discussion}

The results of tests of the compressive strength of the cement stone samples made from the cement paste of normal consistency are shown in Fig. 1.

The analysis of the results of the performed experiments showed that the addition of manganese sludge to the cement binder in an amount of $4 \%$ of the cement mass leads to a maximum increase in the ultimate compressive strength of the cement stone by $17-18 \%$.

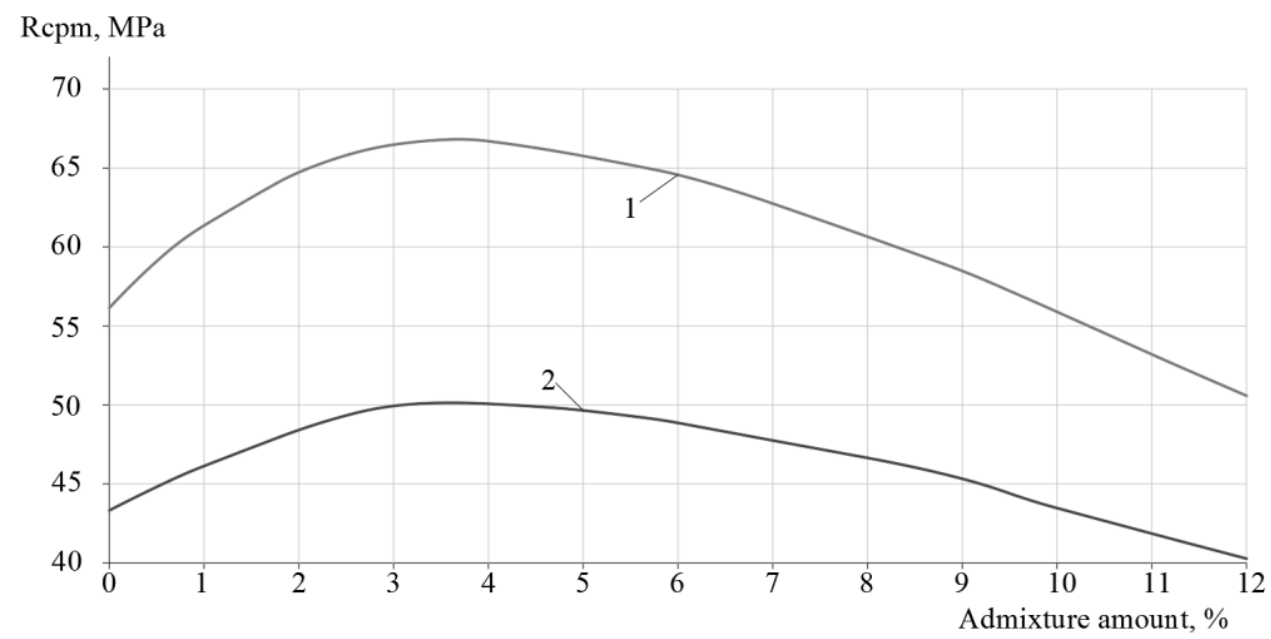

Fig. 1. Influence of the amount of the manganese sludge admixture on the ultimate compressive strength $R_{\text {com }}$ : 1 - of the cement stone, 2 - of the cement-sand mortar.

The results of tests to determine the Portland cement class without and with the manganese sludge admixture are shown in Fig. 1.

The analysis of the results of the performed experiments showed that the manganese sludge admixture to the cement binder in an amount of $4 \%$ of the cement mass leads to a maximum increase in the compressive strength of the cement-sand mortar by $15-18 \%$

When conducting further studies of the effect of the manganese sludge admixture on physical and mechanical properties of a cement binder, manganese sludge was added to the binder in an amount of $4 \%$ of the cement mass, that is, in the amount at which the most durable cement stone was obtained in studies to determine the compressive strength of the cement stone with the sludge admixture. Fig. 2.

The results of tests to determine the plastic strength of the cement paste are shown in 


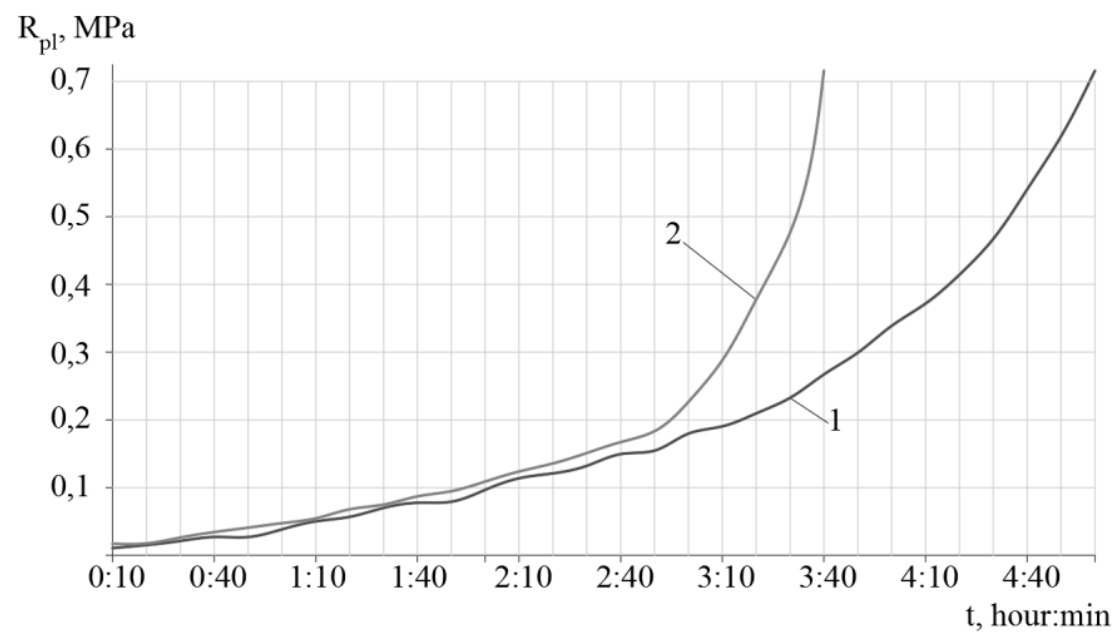

Fig. 2. Kinetics of increase in the plastic strength $\mathrm{R}_{\mathrm{pl}}$ of the cement paste: 1 - the sludge admixture; 2 - with the manganese sludge admixture; $t$ - the age of the cement paste.

The analysis of the results of the performed studies showed that the introduction of the manganese sludge admixture into the cement binder in an amount of $4 \%$ of the cement mass leads to an increase in the rate of the plastic strength development of the cement paste and a reduction in the period of its structure formation by $28-30 \%$, smoothing or complete disappearance of characteristic bends on plastograms, intensive growth of crystalline neoplasms in the cement paste and, as a result, to obtaining the cement stone that is more durable than the cement stone without the sludge admixture.

The results of measuring the velocities of propagation of longitudinal elastic waves through the hardening cement paste and the cement-sand mortar, depending on the age of the mixture, are shown in Fig. 3.

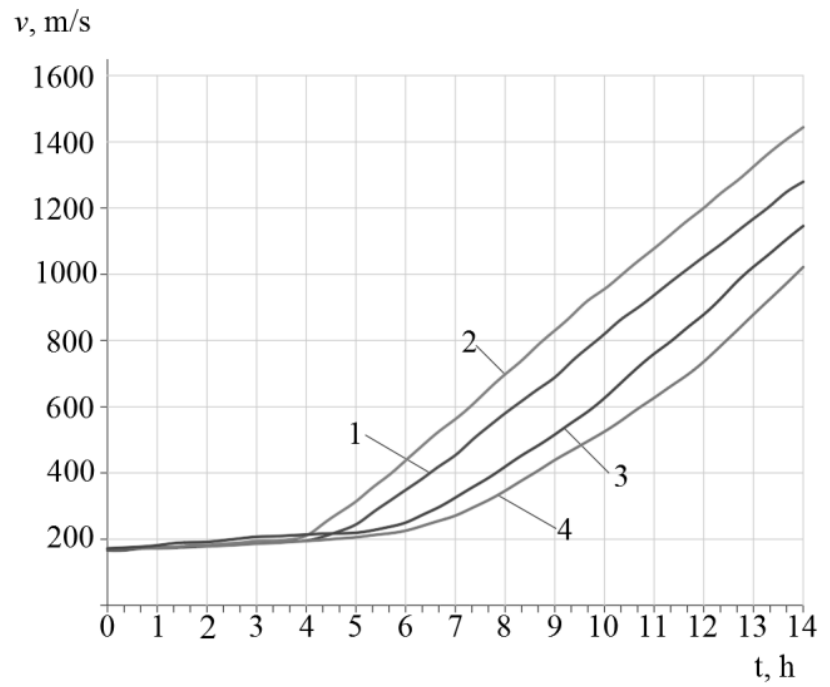

Fig. 3. Dependence of the velocity of propagation of ultrasound $v$ on the age of the cement paste and the cement-sand mortar $t: 1$ - the cement paste without the sludge admixture; 2 - the cement paste with the sludge admixture; 3 - the cement-sand mortar with the sludge admixture; 4 - the cementsand mortar without the sludge admixture.

The analysis of the results of the studies performed showed that the manganese sludge 
admixture to the cement binder in an amount of $4 \%$ of the cement mass reduces the period of the structure formation of the cement paste and the cement-sand mortar by 20 and 40 minutes, respectively. 14 hours after mixing cement with water, the velocity of propagation of longitudinal elastic waves in the structured cement paste and the cement-sand mortar with the sludge admixture increased by $12.2 \%$ and $12.9 \%$, respectively, which indicates an acceleration of the process of the cement paste and the cement-sand mortar strength development due to the manganese sludge admixture to the cement binder.

The results of studies of the change in heat release kinetics during the Portland cement hydration with and without the manganese sludge admixture are shown in Fig. 4.

Analysis of the graphs of heat release during Portland cement hydration with the manganese sludge admixture in the amount of $4 \%$ of the cement mass showed that the maximum temperature of the cement paste with the sludge admixture is higher than the maximum temperature of the cement paste without the sludge admixture by $4.5^{\circ} \mathrm{C}$.

Temperature, $\mathrm{K}$

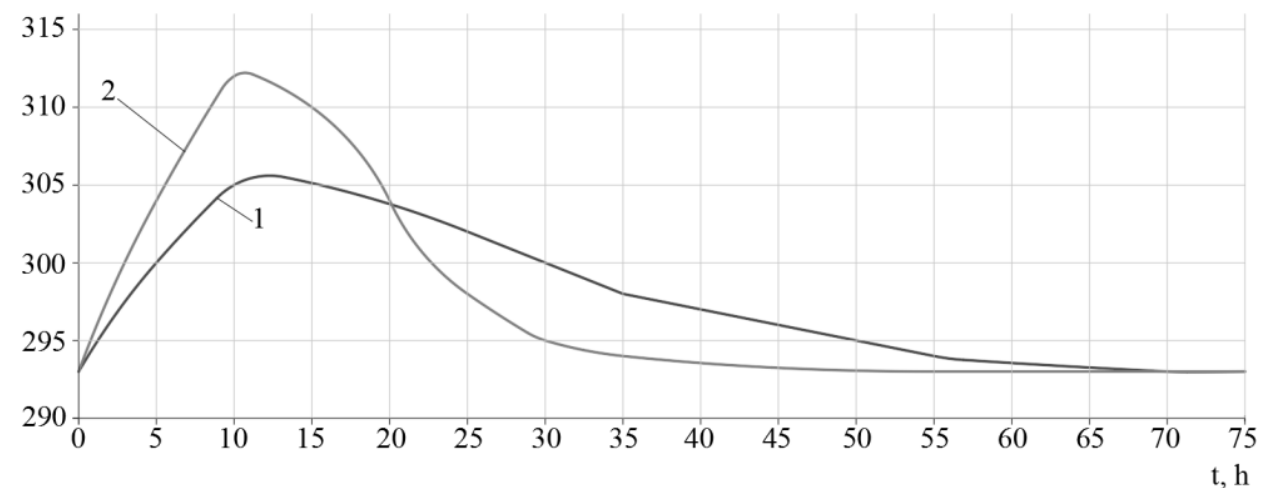

Fig. 4. Effect of the manganese sludge admixture on heat release during Portland cement hydration: 1 - without the sludge admixture; 2 - with the sludge admixture.

At the same time, the sludge admixture reduces the time before the onset of the main effect of heat release from 16 to 11 hours, which indicates an intensification of the cement hydration process with the manganese sludge admixture.

\section{Conclusion}

The addition of dispersed sludge with manganese oxide in an amount of $4 \%$ of the cement mass to a cement binder leads to the activation of the cement hydration process, while the rate of the development of the strength of the cement stone structure increases, the period of its structure formation reduces and the compressive cement stone strength increases by $17-18 \%$, which allows reducing the cement content in structural concrete by $8.8-10.0 \%$ while maintaining its strength, reducing the cost of mine and underground structures and, as a result, reducing the cost of mining.

\section{References}

1. G. Cherdantsev, T. Thurner, International Journal of Oil, Gas and Coal Technology, 4, 390 (2017)

2. V.E. Olkhovatenko, G.I. Trofimova, In the World of Scientific Discoveries, Series A, 2, $62(2014)$ 
3. V.M. Meshram, P.P. Dahale, M.S. Tiwari, S.B. Ramteke, International Journal of Civil Engineering and Technology, 6, 332 (2018)

4. W. Wu, J. Bai, S. Yan, X. Wang, B. Wu, Energy Sources. Part A: Recovery, Utilization, and Environmental Effects (2020)

5. A. Michalak, Business and Economic Horizons, 1, 70 (2014)

6. Y. Wan, W. Li, Systems Science and Control Engineering, 2, 57 (2018)

7. K.S. Sablin, E.S. Kagan, E.S. Chernova, IOP Conference Series: Earth and Environmental Science. International Science and Technology Conference "EarthScience", 062046 (2020)

8. S.A. Zhironkin, G.A. Barysheva, A.A. Khoreshok, M.A. Tyulenev, M.C. Hellmer, IOP Conference Series: Materials Science and Engineering. electronic edition. National Research Tomsk Polytechnic University, 12127 (2016)

9. N. Gilyazidinova, E. Shabanov, X. Liu, E3S Web of Conferences IVth International Innovative Mining Symposium, 01039 (2019)

10. N.V. Gilyazidinova, N.Yu. Rudkovskaya, T.N. Santalova, The 8th Russian-Chinese Symposium Coal In The 21st Century: Mining, Processing And Safety, 62 (2016)

11. N.V. Gilyazidinova, V.B. Duvarov, A.S. Mamytov, E3S Web of Conferences Vth International Innovative Mining Symposium, 01012 (2020)

12. S. Chowdhury, M. Mishra, O. Suganya, Ain Shams Engineering Journal, 6-2, 429 (2015)

13. Cheah Chee Ban, Ramli Mahyuddin. Construction and Building Materials, 30, 320 (2012)

14. C. Kulasuriya, V. Vimonsatit, W.P.S. Dias, P. De Silva, Construction and Building Materials, 68, 426 (2014)

15. M.S. Konsta-Gdoutos, Z.S. Metaxa, S.P. Shah, Cement and Concrete Research, 40-7, 1052 (2010)

16. A.V. Uglyanica, T.V. Khmelenko, K.D. Solonin, International Journal of Applied Engineering Research, 22, 16837 (2014)

17. A. Kargin, A. Uglyanica, V. Baev, N. Mashkin, AIP Conference Proceedings. Proceedings of the II All-Russian Scientific Conference of Young Scientists "Advanced Materials in Technology and Construction", 070009 (2016)

18. A.V. Uglyanitsa, N.V. Gilyazidinova, N.Y. Rudkovskaya, T.N. Santalova // International Journal of Applied Engineering Research, 8, 19235 (2015) 